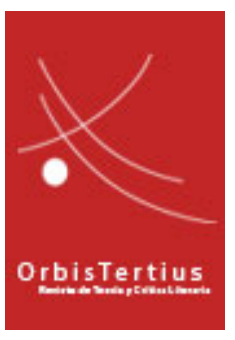

Orbis Tertius, vol. XXIII, nº 27, e069, junio 2018. ISSN 1851-7811

Universidad Nacional de La Plata

Facultad de Humanidades y Ciencias de la Educación

Centro de Estudios de Teoría y Crítica Literaria

\title{
Idas y vueltas de una mirada: impresiones del gaucho Martín Fierro en la exhibición de Los treinta y tres de Juan Manuel Blanes
}

\section{Juan Albín * \\ * Universidad de Buenos Aires, Argentina.}

Cita sugerida: Albín, J. (2018). Idas y vueltas de una mirada: impresiones del gaucho Martín Fierro en la exhibición de Los treinta y tres de Juan Manuel Blanes. Orbis Tertius, 23 (27), e069. https://doi.org/10.24215/18517811e069 


\section{Idas y vueltas de una mirada: impresiones del gaucho Martín Fierro en la exhibición de Los treinta y tres de Juan Manuel Blanes}

Juan Albin

Universidad de Buenos Aires, Argentina

\section{Resumen:}

En la "Carta que el gaucho Martín Fierro dirige a su amigo D. Juan Manuel Blanes con motivo de su cuadro Los treinta y tres” (1878), José Hernández hace volver a Martín Fierro - un año antes de que publique la Vuelta- desde tierra de indios hacia la ciudad para ver una exposición de Blanes y comentarla. Esa carta puede leerse como un comentario crítico sobre la obra de Blanes y su exposición, en la serie de otros que se publicaron en la prensa porteña; también, como una producción que parte de la obra de Blanes pero la desarrolla productivamente, la sitúa en otro contexto -el de la literatura gauchesca- y la interpreta, versionándola.

Palabras clave: Literatura gauchesca- Pintura histórica - Transposición - Ekphrasis - Crítica artística.

\section{Abstract:}

In the "Carta que el gaucho Martín Fierro dirige a su amigo D. Juan Manuel Blanes con motivo de su cuadro Los treinta y tres” (1878), José Hernández brings back Martín Fierro - a year before his Vuelta is published- from indian land and into the city to look at and comment on an exhibition of works by the artist Juan Manuel Blanes. This letter may be interpreted as a critical commentary on Blanes' work, in line with other commentaries published in the city's press; and also, as a literary production that draws from Blanes' work but at the same time develops it productively, thus placing it in a different context -that of gauchesca literature- as well as interpreting and creating a new version of it.

KeYWORDS: Gauchesca literature - Historical Painting - Transposition - Ekphrasis - Artistic Criticism.

\section{Blanes y Hernández: de la pintura de historia a la poesía gauchesca}

En 1878 Juan Manuel Blanes expone exitosamente su cuadro Juramento de los Treinta y Tres Orientales (Figura 1) en Montevideo y habiendo logrado un éxito considerable el mismo año lo trae a Buenos Aires, donde se exhibe en el salón de los altos de la casa Fusoni y Maveroff. También en Buenos Aires la obra tiene una recepción muy efectiva y elogiosa: a la inauguración asiste el presidente Nicolás Avellaneda y desde entonces se suceden un discurso de Luis V. Varela, elogios de Carlos Tejedor y Domingo F. Sarmiento, según informa Ribera (1985: 335). Me interesa, en esa serie de repercusiones textuales, una en particular. José Hernández escribe entonces un poema titulado "Carta que el gaucho Martín Fierro dirige a su amigo D. Juan Manuel Blanes con motivo de su cuadro Los treinta y tres”, ${ }^{1}$ texto en que Hernández hace que el gaucho Martín Fierro entre a ver la exposición de Blanes y comente el cuadro.

¿Por qué ese recorte? ¿Por qué Blanes y Hernández? Me interesa pensar y estudiar las relaciones entre la palabra y la imagen en el siglo XIX, y para ello Hernández y Blanes se revelan muy productivos. Por un lado, Blanes es un artista cuyas exhibiciones -según ha mostrado Laura Malosetti Costa en su estudio sobre la recepción de Un episodio de la fiebre amarilla (2007: 70) - dan que hablar: la exhibición de sus cuadros hace que en la prensa se escriba abundantemente, y se escriba sobre arte (sobre la luz, el claroscuro, el color y la composición) en un campo cultural en que ello no es frecuente. Su producción pictórica, entonces, provoca textos, escritura, comentarios críticos. Por otro lado, Hernández ha mostrado como escritor un 
interés particular en la imagen visual, y ello se deja ver en La vuelta de Martín Fierro, cuya edición en 1879 Hernández acompaña con grabados de Clerice, mostrándose especialmente preocupado por la articulación entre palabra e imagen.

¿Y por qué abordar específicamente el Juramento de los treinta y tres orientales de Blanes y el texto de Hernández que lo comenta? Precisamente, porque me permite plantear el problema de la articulación entre imagen y escritura de un modo que no es el más habitual. Si por lo general se ha tendido a pensar que la imagen vendría a ilustrar lo que se encontraría previamente en un texto, en cambio a mí me interesa problematizar esa concepción un poco esquemática, y para ello pensar los modos complejos en que no solo la literatura hizo producir imágenes, sino también los modos en que la pintura hizo producir literatura. En este sentido, el Juramento de los treinta y tres produce literatura: hace que Hernández, hacia 1878 (un año antes de que publique La vuelta de Martín Fierro), haga volver a Martín Fierro desde Tierra Adentro hacia la ciudad para ver un cuadro de Blanes en el salón de la casa Fusoni y Maveroff y comentarlo. Y desde ya es significativa la forma del texto de Hernández: se trata de 33 sextinas. ${ }^{2}$ La obra de Blanes funciona en ese sentido como un disparador productivo que decide, desde el inicio, una suerte de matriz formal para el texto.

Tanto en Montevideo como en Buenos Aires la exhibición del cuadro de Blanes se dio como un espectáculo que excedió lo meramente visual. En Montevideo, por ejemplo, la exhibición contó con coronas y ramos de flores que se depositaban al pie del cuadro, pastillas aromáticas que se encendían junto a él, poemas que se leían oralmente para exaltar la "gloria inmortal" de la escena representada, textos escritos en prosa y en verso que se dejaban como mensajes en el salón. ${ }^{3}$ La exhibición por tanto no fue únicamente un acontecimiento visual, sino que apuntaba a estimular de modo múltiple los sentidos. En Buenos Aires sucedió algo parecido con la exhibición del cuadro de Los treinta y tres. Algunos diarios porteños (como La Tribuna y El Nacional) anuncian en repetidas ocasiones diversos conciertos musicales en la misma sala en donde se exhibe el cuadro. El Nacional, por ejemplo, anuncia el 24 de julio de 1878, en un artículo titulado "Exposición de cuadros", la apertura de la exposición informando que "las bandas de música tocarán el Himno Argentino y Oriental, y se leerán varias composiciones literarias”. Nuevamente, entonces: en la exhibición confluyen imágenes, música y literatura. ${ }^{4}$

Pero no solo se declaman poemas en el espacio de exhibición del cuadro en Montevideo y en Buenos Aires. También esos poemas se publican, en ocasiones, por la prensa. Es el caso del poema que escribe para la ocasión Pedro Bernat, poeta español: poema titulado significativamente "El cuadro-poema", publicado en El Siglo de Montevideo y recogido luego por La Tribuna de Buenos Aires el 12 de enero de 1878. Texto que juega desde su título hasta tal extremo con los cruces entre los códigos de la pintura y la poesía que es difícil saber a qué se refiere: si al poema o al cuadro, o a ambos. Esos cruces entre códigos diversos también son notorios en el poema que José Hernández escribe en la misma ocasión.

Este poema -propongo- puede leerse como un comentario crítico sobre la obra de Blanes y su exposición, en la serie de otros que se publicaron en la prensa porteña; también, como una producción que parte de la obra de Blanes, pero la desarrolla productivamente, la sitúa en otros contextos (los de la gauchesca y de la propia textualidad de Martín Fierro) y por tanto la interpreta: en ese sentido, la versiona. ¿Cómo la completa? ¿Cómo la versiona? Precisamente, al describir e interpretar la imagen traspasándola ${ }^{5}$ al código de la gauchesca: si el código de la literatura gauchesca consiste de modo sintético en una escritura que se escribe como si estuviera hablando un gaucho, lo que hace permanentemente el poema de Hernández con el cuadro de Blanes es no solo describir las figuras representadas visualmente sino darles asimismo una voz gaucha. ${ }^{6}$ La proclama de Lavalleja, en el mismo gesto de levantar y mostrar la bandera de los juramentados, se vuelve así una proclama gaucha: “'ande quiera / que flamé se ha de triunfar, / vengo resuelto a peliar / y que me siga el que quiera." (Hernández 2014: 102). Ekphrasis en su sentido restringido (en tanto género poético menor dedicado a la representación y al comentario verbal de obras de arte visuales), esta ekphrasisgauchesca recurre a los dos procedimientos básicos del género: describe la obra de arte pero también hace hablar (le 
da una voz) a ese objeto mudo. ${ }^{7}$ Por ello no llama la atención que, en esa dirección, tanto Ricardo Rojas como Tulio Halperín Donghi hayan detectado los dos procedimientos básicos del poema: describir las figuras (su apariencia externa, sus ropas y sus armas, su pose, su gesto, su expresión), por un lado; interpretar su interioridad, dotándolas de una voz, por otro. ${ }^{8}$ En efecto, por esos dos procedimientos (pero sobre todo por el segundo: el dotar a esas figuras de una voz), el poema versiona el cuadro a la gauchesca.

\section{El crítico como artista}

“¿Pero es la crítica realmente un arte creativo?”, pregunta Ernest en El crítico como artista (1891) de Oscar Wilde. Gilbert responde: “¿Por qué no debería serlo? Ella trabaja con materiales, y les da una forma que es a la vez nueva y placentera. ¿Qué más uno puede decir acerca de la poesía?” (Wilde, 1952: 966, la traducción es mía). Así, según lo que se plantea en este diálogo de Wilde, la crítica de una obra de arte es o debería ser, ella misma, una obra de arte. Eso es lo que me interesa plantear en el análisis del poema de Hernández sobre el cuadro de Blanes. El poema podría ser considerado, en primer lugar, como un comentario crítico. ¿Qué es lo que capta la atención de nuestro particular crítico? ¿A qué se dirige su mirada y cómo se mueve por el cuadro?

\section{La exposición: Martín Fierro en el salón}

En principio, Martín Fierro no solo repara en el cuadro, sino en el mismo acontecimiento de su exhibición. Hay, en efecto, una serie de estrofas en el poema de Hernández que prestan especial atención a algunos aspectos de la exhibición. Así, la tercera y la cuarta estrofa centran su atención en la entrada de Fierro a la exposición y, centralmente, en el pago de la entrada:

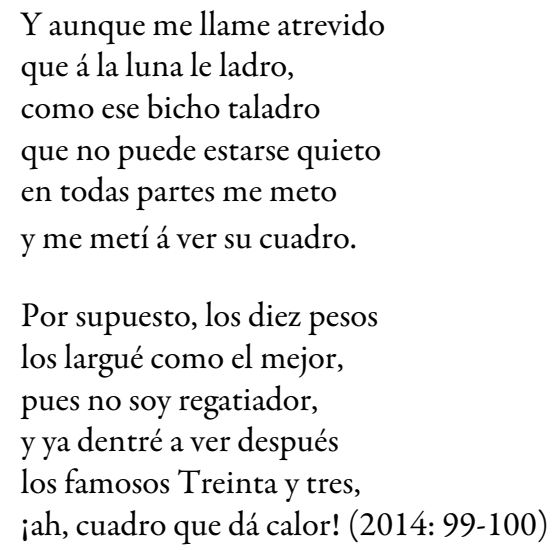

Dos comentarios sobre estas dos estrofas. En primer lugar, hay que notar el modo en que Fierro narra cómo se "mete" a ver el cuadro y percibir su sensación de incomodidad: sensación de estar fuera de lugar, sensación del que se ha "atrevido" a entrar en un lugar al que no debe entrar, sensación del que se siente "bicho" fuera de lugar. Metido, colado en una exposición. Pero enseguida aclara: "por supuesto, los diez pesos, / los largué como el mejor". Fierro ha pagado y solo entonces entra a ver los famosos Treinta y tres. El énfasis en la entrada y su precio hace percibir el aspecto económico de todo espectáculo -incluso los de las bellas artes- y Fierro retomará el tema al final del poema, cuando ya esté concluyendo: luego de explicar que no va a meter a los treinta y tres orientales en su "coplada" para no cansar, confiesa lo siguiente: "Yo le saqué los diez pesos / al cuadro, tanto mirarlo" (2014: 106). Los diez pesos han valido la pena: no solo de tanto mirar el cuadro se ha recuperado el costo de la entrada, sino que la visión del cuadro ha terminado siendo una inversión y ha engendrado ganancias: esto es, el mismo poema, la misma "coplada" que estamos leyendo en la carta de Fierro. $^{9}$ 
La entrada, tanto en su aspecto espacial-cultural como en su carácter económico, no es lo único que llama la atención de Fierro en la exposición. En la sexta estrofa se puede leer lo siguiente: "Encima han acomodao / un sol que valdrá un tesoro: / Lo habrán puesto, no lo inoro / como en el naipe español; / porque habrán dicho esos toros: / 'a todos alumbra el sol'” (2014: 100). Aunque la estrofa es de difícil interpretación (no termina de decidirse si Fierro se refiere a la luz - "el sol"- que ilumina artificialmente el cuadro o a la luz misma que el artista le ha dado a su cuadro al representar una escena de amanecer), me inclino por la primera opción (la luz artificial que ilumina el cuadro en la exhibición), porque el poema busca insertarse de ese modo en una especial tradición dentro de la literatura gauchesca.

En efecto, al trabajar estos tópicos (la entrada -económica y espacial- al salón y su iluminación) el poema se inserta desde el inicio en una vertiente interna de la gauchesca que se remonta a Bartolomé Hidalgo y se consuma en Estanislao del Campo: la de los poemas gauchescos que narraban la visita del gaucho a la ciudad y a sus espectáculos. Quizás aquí habría que remontarse no únicamente al Fausto (1866) de del Campo, cuyo subtítulo es Impresiones del gaucho Anastasio el Pollo en la representación de esta ópera, sino más específicamente a ese esbozo previo al Fausto que fue la "Carta de Anastasio el Pollo sobre el Beneficio de la Sra. La Grúa” (1857), otra carta gauchesca - como la que Fierro le envía a Blanes- en que se pueden encontrar los dos tópicos que Hernández reelabora: la entrada al espacio cultural (que hay que pagar); la iluminación artificial (ante la cual el gaucho queda fascinado, percibiéndola o comparándola con el sol). Otros dos aspectos del poema de Hernández lo vinculan con esa vertiente de la gauchesca de la que programática y críticamente se había distanciado en la "Carta a Zoilo Miguens" que prologa la $I d a .{ }^{10}$ Por un lado, el ilusionismo inicial del que parece objeto la mirada de Fierro: en principio se queda "azorao" frente a la "comitiva" representada en el cuadro y dice lo siguiente: "La miré de abajo arriba / pero, ique el diablo me lleve!, / si parece que se mueve / lo mesmo que cosa viva" (2014: 100). Por otro lado, ese ilusionismo lleva a Fierro a identificarse con los personajes representados e incluso al deseo de intervenir en la escena, metiéndose en el cuadro: "Y esa gente tan dispuesta / Que su país va a libertar, / no se les puede mirar / sin cobrarles afición... / iHasta quisiera el mirón / poderles acompañar!" (2014: 100). Todo ello - proponemos- sitúa esta composición de Hernández en una vertiente de la gauchesca cercana a la del Fausto de Estanislao del Campo. ${ }^{11}$

Ludmer (2000) ha propuesto que esa vertiente interna dentro del género gauchesco ha tendido a una progresiva modernización, despolitización y autonomización del género. Así, de las fiestas cívicas por el 25 de Mayo y sus espectáculos (representados en la "Relación que hace el gaucho Ramón Contreras a Jacinto Chano de todo lo que vio en las Fiestas Mayas de Buenos Aires, en el año 1822" de Hidalgo) se pasa a la representación de la ópera Fausto en el teatro Colón, a partir de la cual se escribe el Fausto de Del Campo: desplazamiento que se duplica -de modo metafórico- en el desplazamiento de la crónica civil a la crónica cultural y finalmente teatral (Ludmer 2000: 204-205). Se podría decir entonces que la “Carta...” de Hernández da un paso más en esa trayectoria: de la crónica teatral u operística se pasa ahora a una suerte de crítica artística. ${ }^{12} \mathrm{Y}$ sin embargo Hernández le da una nueva vuelta a esta vertiente del género: la obra que el gaucho Martín Fierro contempla y comenta representa un acontecimiento central para la historia política del Uruguay y por tanto reinstala lo político en el centro del poema de Hernández.

\section{El cuadro: los treinta y tres por Martín Fierro}

Así, luego de una serie de comentarios sobre algunos aspectos de la exposición (la entrada al salón y su iluminación), Fierro realiza también un comentario muy preciso sobre algunas de las figuras representadas en el cuadro. Es interesante observar en qué figuras se detiene Fierro y cuáles captan su mirada: graficar y pensar, por tanto, las derivas y los desvíos de la mirada de Fierro.

Francisco de Mendoza, en un texto publicado hacia 1870 y titulado Manual del pintor de historia, texto que puede servir para detectar algunas convenciones cristalizadas de este género pictórico, recomendaba 
colocar a las figuras, los personajes o los héroes principales en el centro del cuadro, para que el espectador "sin querer fije en ellos su atención" (Mendoza 1870: 33). ${ }^{13}$ Esa recomendación buscaba reglamentar tanto la producción como la recepción del cuadro: por medio de una reglamentación de la composición, buscaba dirigir la atención del futuro receptor. Pero si bien en un primer momento la mirada de Fierro se va a dirigir al centro del cuadro y a su figura central y privilegiada (la de Lavalleja), en seguida se va a desviar para dirigirse a los márgenes del cuadro. Las estrofas octava, novena y décima ponen el foco en el centro del cuadro y en su figura principal, pero lo hacen de un modo particular:

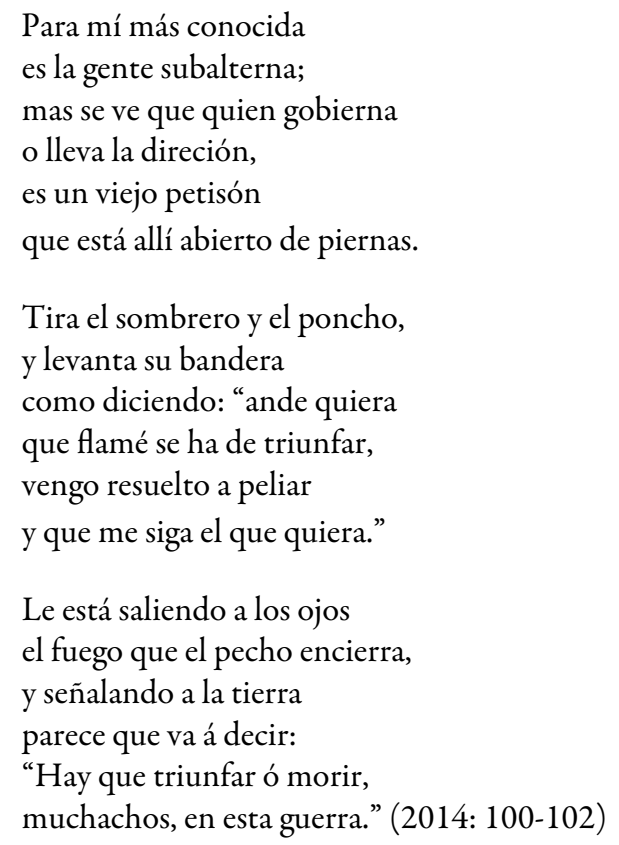

Varias observaciones sobre estas estrofas. En primer lugar, la identificación y el reconocimiento de Fierro, como en un espejo, con ciertos personajes: "Para mí más conocida / es la gente subalterna." Esa palabra, "subalterna", me interesa especialmente, porque allí la mirada de Fierro recupera críticamente algo que podía observarse en el cuadro de Blanes. Si la pintura de historia tal como Blanes la practica construye mitos fundacionales de la comunidad nacional (ver Peluffo Linari 2002) y para ello construye y representa alianzas en función de un enemigo común (jefes y soldados, letrados y gauchos, argentinos y orientales, todos unidos en función del enemigo común: los portugueses), no deja de hacer visibles de todos modos las diferencias articuladas en la alianza. ${ }^{14}$ Así, lo que Martín Fierro percibe en el cuadro es subordinación: jefes y subalternos: es decir, diferencias, una comunidad dividida. Y se identifica, de entrada, con la "gente subalterna", al mismo tiempo que convierte al héroe idealizado de este mito fundacional -en una línea decididamente cómica y picaresca que La vuelta del Martín Fierro va a potenciar- en un “viejo petizón” y “abierto de piernas". Las proporciones de ese cuerpo heroico y su misma pose, que según las recomendaciones del manual de Francisco de Mendoza deberían idealizarse en una pintura de historia (1870: 28), son percibidas de modo invertido por la mirada de Martín Fierro. Así, su mirada degrada al Lavalleja de Blanes en sus proporciones (lo hace petizo) y en su pose (lo ve demasiado abierto de piernas), y así corroe de un modo humorístico la figura del héroe.

Si en las primeras estrofas del poema Fierro se ocupa de la figura central, en seguida desvía su mirada hacia los márgenes del cuadro. El movimiento de esta mirada crítica va del centro a los márgenes: de la figura que representa a Lavalleja a aquella figura que sostiene una "crucesita", de la figura central del cuadro a este detalle ínfimo que llama la atención de Fierro y que sacraliza la escena del juramento patriótico desde el margen. ${ }^{15}$ A continuación Fierro se detiene en el grupo de figuras del que forma parte la figura de la crucecita (a la izquierda del cuadro): en primer lugar, la figura de un criollo con poncho, bota fina y "garabina"; en segundo lugar, una figura en camiseta, muy arremangada, que parece "soldao", según la mirada de Fierro, pero se ve que en un tiempo pasado fue un "desalmao". ${ }^{16}$ La rima yuxtapone de modo brusco dos elementos que a Fierro 
le interesan especialmente en estas figuras: figuras que están en los márgenes, las de los meros soldados, pero también las de los "soldaos" ${ }^{17}$ que en tiempos pasados han sido "desalmaos": es decir, figuras que si hoy están bajo la ley de la comunidad ayer estaban sustraídas a ella.

Otras dos figuras concretas captan especialmente la atención de Fierro, atraída por la valentía de esos cuerpos representados en el cuadro: en primer lugar, la del gaucho arrodillado en el centro, que funciona como contrapunto de la figura erguida de Lavalleja; en segundo lugar, la de un gaucho con el que Fierro se identifica ya de modo más pleno: "Pero entre tanto valiente / dende lejos se divisa / el que en mangas de camisa / se hace notar el primero. / Un gaucho más verdadero / no he visto ni en los de Urquiza" (2014: 104). Gaucho verdadero, gaucho valiente, gaucho como los de antes, gaucho como los de Urquiza: gaucho con el que Fierro podrá identificarse plenamente y cuya valentía se acerca a lo temerario: este otro gaucho -como el anterior, arrodillado- parece también dispuesto a la pelea e incluso "Muestra ser, por la figura, / sin asco para matar" (2014: 105). La mirada de Fierro se ha ido desplazando de la izquierda a la derecha y ahora se posa en la figura de este gaucho, que ocupa un lugar privilegiado en la economía interna del poema: si a Lavalleja le dedicaba tres sextinas, a esta figura Fierro le dedicará cinco sextinas, describiendo con mucha precisión sus prendas gauchas y sus armas: gaucho en mangas de camisa, con espuelas y botas de potro, medio escaso el chiripá, manea, dragona, trabuco. La atención exhaustiva que Fierro le dedica a esta figura y a sus prendas parece haber sido proporcional al trabajo que Blanes puso en su construcción: se conservan numerosos bocetos en que Blanes trabaja y ensaya una y otra vez sobre la figura de este gaucho: ese trabajo da su resultado y retiene la mirada de Fierro. Si respecto de la anterior figura -la del gaucho arrodillado- había gusto ("no deja de gustarme", decía Fierro), ahora hay una más plena identificación: así como Fierro se viste con sus mejores prendas gauchas antes de marchar hacia la frontera en El gaucho Martín Fierro, ${ }^{18}$ el gaucho del cuadro de Blanes tampoco ha descuidado sus prendas para ir a la guerra: "En el amor y en la guerra, / en todo habrá sido igual; / tiene en trance tan formal, / el enemigo en contorno; / pero no olvidó el adorno / de cola de pavo-rial" (2014: 104).

Fierro dirigirá su mirada finalmente a otros dos elementos o detalles del cuadro. Así, la mirada de Fierro vuelve a pasar de la derecha a la izquierda del cuadro y se dirige a un detalle ínfimo que condensa nuevamente su manera de mirar. Mirada impresionista, que se desvía y deriva de un lado al otro, la mirada de Fierro no deja de ser crítica: crítica impresionista, podría decirse, así como las impresiones del gaucho Anastasio el Pollo en el Fausto de Estanislao del Campo no son impresiones ingenuas sino críticas tanto de la ópera como del espacio social en que se representa (Anderson Imbert 1968; Schvartzman 2013). Porque, ¿a qué le presta finalmente su atención Fierro? En primer lugar, la mirada de Fierro se posa en uno de los conjuntos de prendas y armas que Blanes representa arrojados en la arena y lo primero que piensa al respecto es significativo: "alguno se ha hecho avestruz", es decir, alguno o algunos han desertado. ${ }^{19}$ Esa reflexión conduce su mirada a otro detalle del cuadro: Fierro repara ahora en los que, en efecto, huyen: "A la distancia se llevan / el bote los marineros, / los mesmos que los trujeron / se retiran apurados" (2014: 106). Es evidente que Fierro quiere interpretar ese detalle en una dirección determinada. Porque esa barca y el gesto de esos "marineros" podrían interpretarse tanto en movimiento de retirada como en movimiento de llegada, pero Fierro prefiere verlos huyendo: es decir, desertando. En estas pequeñas opciones interpretativas su mirada se revela como mirada crítica... Yaquí Martín Fierro termina haciendo, insospechadamente, a seis años de la publicación de El gaucho Martín Fierro y a un año de la publicación de La vuelta de Martín Fierro, una defensa de la leva, es decir, del reclutamiento forzado: "Yo los hubiera agarrao, / a los que el bote se llevan; / justo es que a todo se atreva / el hombre que hace la guerra; / cuanto pisaron en tierra / debió principiar la leva". Mirada impresionista, mirada atenta a los detalles más mínimos y marginales del cuadro, como el de esas figuras de los que huyen en la barca, no deja de ser crítica y señalar algo que se encuentra en la tela de Blanes pero que la recepción (y tal vez la compra) oficial del cuadro por el gobierno uruguayo neutralizó o recubrió: el orden compositivo del cuadro -el modo en que organiza y ordena los grupos de figuras - no sólo exhibe en términos simbólicos alianzas sino también jerarquías. ${ }^{20}$ Y aun proclamando "la leva" (palabra por lo demás ausente en el poema de 1872, que 
opta -para mentar ese mundo político y militar que destruye la vida del gaucho- por un léxico ruralizante), eso ve aún Fierro en 1878: jerarquía, subordinación, diferencias. Entre los pretendidamente épicos treinta y tres orientales de Blanes Martín Fierro percibe contrastes y distorsiones: jefes y subordinados, desalmados devenidos patriotas, desertores.

Mirada a la vez impresionista y distorsiva en su atención a los detalles marginales, la de Martín Fierro en la "Carta..." es parte de una serie más amplia. La literatura gauchesca mostró un particular interés por los espectáculos y las imágenes: ${ }^{21}$ en esa serie, el hecho artístico siempre fue objeto de una mirada corrosiva, atenta tanto a la representación como a su marco. Mirada distorsiva y corrosiva, hemos dicho: bufa, ha propuesto Leónidas Lamborghini, que pensó la gauchesca como un arte bufo que permanentemente devolvió al sistema y al poder, multiplicadas paródicamente, sus propias distorsiones (Lamborghini: 2003). Así, si las publicaciones gauchescas se interesaron muy temprana y sostenidamente por las imágenes para ilustrar sus impresos, los textos del género frecuentemente también transpusieron y comentaron crítica y corrosivamente imágenes artísticas. En esa particular serie de ekphrasis gauchescas, el poema de Hernández señala un momento culminante en lo que toca al interés del género por las imágenes, se inscribe en la serie de los poemas gauchescos que narraban el viaje del gaucho a la ciudad y su participación en los espectáculos urbanos, y vuelve a plantear de manera compleja -como lo había hecho también, de otros modos, el Faustolas relaciones entre arte, literatura y política.

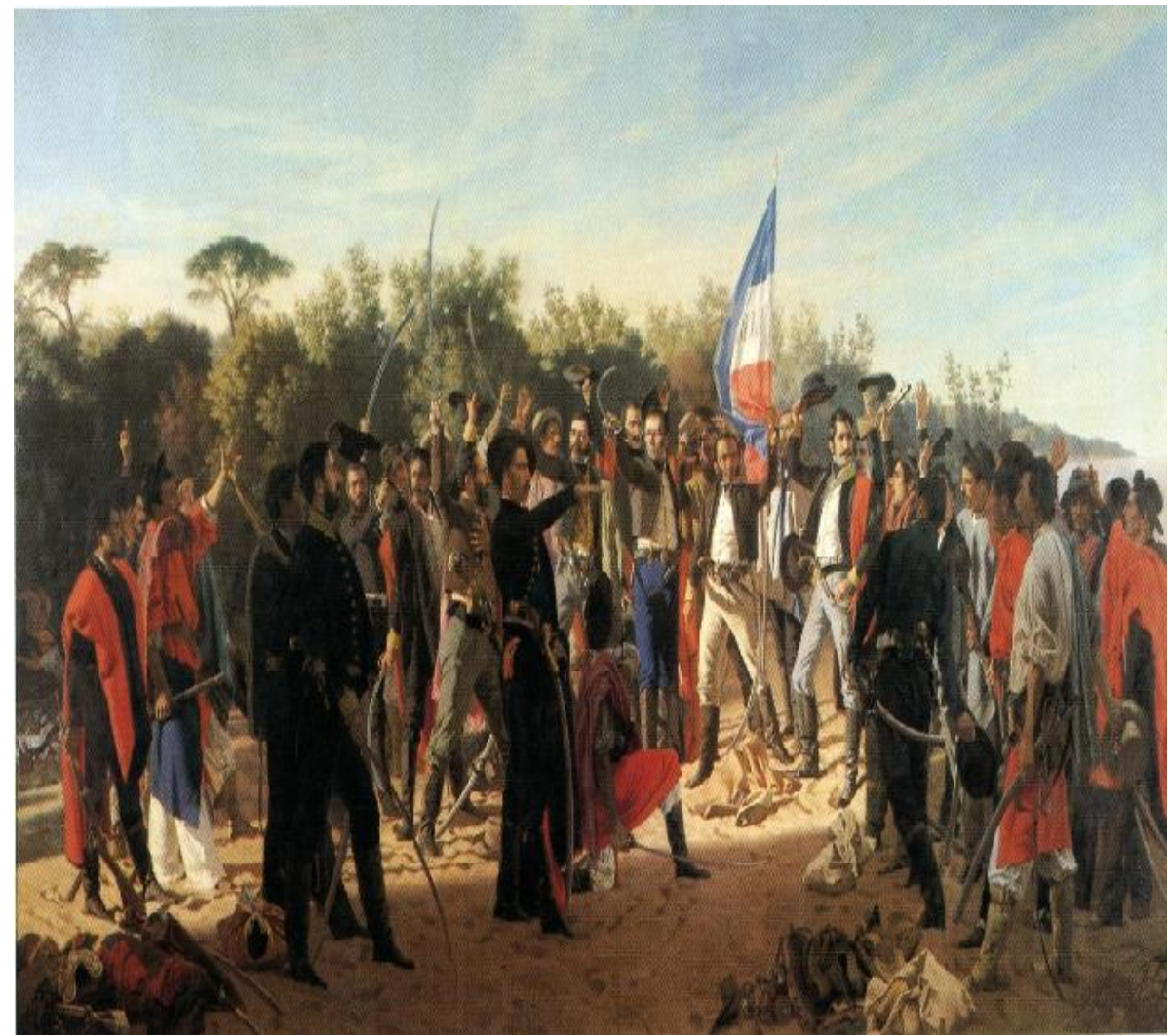

Figura 1: Juan Manuel Blanes: Juramento de los Treinta y Tres Orientales (1875-1878) Óleo sobre tela. 311 x $564 \mathrm{~cm}$. Museo de Bellas Artes Juan Manuel Blanes, Montevideo, Uruguay. Museo de Bellas Artes Juan Manuel Blanes

\section{BIBLIOGRAFÍA}

Amigo, Roberto (2002). “Región y Nación. Juan Manuel Blanes en la Argentina”, en Juan Manuel Blanes. La Nación naciente (1830-1901), Montevideo, Museo Municipal de Bellas Artes Juan Manuel Blanes. 
Anderson Imbert, Enrique (1968). Análisis de "Fausto", Buenos Aires, Centro Editor de América Latina.

Bernat, Pedro A. (1878). "El cuadro-poema”, en La Tribuna, Buenos Aires, 12 de enero.

Campo, Estanislao del (1989). "Carta de Anastasio el Pollo sobre el Beneficio de la Sra. La Grúa”, en Fausto. Su prefiguración periodistica, Ángel J. Battistessa (ed.), Buenos Aires, Academia Argentina de Letras.

Gamboni, Dario (2007). “La crítica de arte en la encrucijada de las representaciones”, en Gabriela Siracusano (ed.), Las tretas de lo visible. Buenos Aires, Centro Argentino de Investigadores de Arte.

Genette, Gerard (1989). “Transposición”, en Palimpsestos. La literatura en segundo grado, Madrid, Taurus.

Halperín Donghi, Tulio (1985). "Nacimiento y metamorfosis de Martín Fierro”, en José Hernández y sus mundos, Buenos Aires, Editorial Sudamericana.

Hernández, José (2001). Martín Fierro, Élida Lois y Ángel Núñez (eds.), Madrid, ALLCA XX / Colección Archivos.

Hernández, José (2014). "Carta que el gaucho Martín Fierro dirige a su amigo D. Juan Manuel Blanes con motivo de su cuadro Los treinta y tres”, en Obra periodística. Periodismo Gauchipolítico. La Reforma Pacifica. El Nacional Argentino. El Litoral, Segunda edición ampliada, Ángel Núñez (ed.), Buenos Aires, Editorial Docencia.

Hidalgo, Bartolomé (1940). "Diálogo entre Jacinto Chano, capataz de una estancia en las islas del Tordillo, y el gaucho de la Guardia del Monte”, en Eleuterio F. Tiscornia (ed.), Poetas gauchescos. Hidalgo, Ascasubi, Del Campo, Buenos Aires, Losada.

Lamborghini, Leónidas (2003). “El gauchesco como arte bufo", en Julio Schvartzman (dir. del volumen), La lucha de los lenguajes, volumen II de Noé Jitrik (dir. de la obra), Historia critica de la literatura argentina, Buenos Aires, Emecé.

Ludmer, Josefina (2000). "En el paraíso del infierno. El Fausto argentino. Un pastiche de crítica literaria”, en El género gauchesco. Un tratado sobre la patria, Buenos Aires, Libros Perfil.

Malosetti Costa, Laura (2007) "La hora de Blanes", en Los primeros modernos. Arte y sociedad en Buenos Aires a fines del siglo XIX, Buenos Aires, Fondo de Cultura Económica.

Mendoza, Francisco de (1870). Manual del pintor de historia, o sea recopilación de las principales reglas, máximas y preceptos para los que se dedican a ésta profesión, Madrid, Imprenta de T. Fortanet.

Mitchell, W. J. T. (1994). "Ekphrasis and the Other", en Picture Theory, Chicago, The University of Chicago Press.

Peluffo Linari, Gabriel (2002). "Los íconos de la nación. El proyecto histórico-museográfico de Juan Manuel Blanes", en Juan Manuel Blanes. La Nación naciente (1830-1901), Montevideo, Museo Municipal de Bellas Artes Juan Manuel Blanes.

Peluffo Linari, Gabriel (2009). Historia de la Pintura Uruguaya. Tomo I. El imaginario nacional-regional (1830-1930): De Blanes a Figari, Montevideo, Ediciones de la Banda Oriental.

Ribera, Adolfo Luis (1985). "La pintura”, en Historia General del Arte en la Argentina, Tomo III, Buenos Aires, Academia Nacional de Bellas Artes.

Rojas, Ricardo (1937). Otros versos de Martín Fierro. Publicaciones del Instituto de Literatura Argentina, Sección de Crítica, Tomo I, $N^{\circ} 10$, Buenos Aires, Imprenta de la Universidad.

Salterain y Herrera, Eduardo de (1950). Blanes. El hombre, su obra y la época, Montevideo, Impresora Uruguaya.

Schvartzman, Julio (1996). "El gaucho letrado", en Microcrítica. Lecturas argentinas (cuestiones de detalle), Buenos Aires, Biblos.

Schvartzman, Julio (2013). Letras gauchas, Buenos Aires, Eterna Cadencia.

Steimberg, Oscar (1993). "Libro y transposición” y "El pasaje a los medios de los géneros populares”, en Semiótica de los medios masivos, Buenos Aires, Atuel.

Wilde, Oscar (1952). “The Critic as Artist”, en The Works of Oscar Wilde, London, Collins. 


\section{Notas}

1 Trabajo con la edición del poema publicada por Ángel Núñez en José Hernández (2014: 99-106), que incluye asimismo la reproducción facsimilar de la hoja suelta del diario La Nación de Montevideo del 20 de agosto de 1878, en la que se publica el texto por primera vez. Conservo, asimismo, la ortografía de esa edición. A partir de aquí llamaré "Carta..." al texto de Hernández.

2 No podemos dejar de pasar la oportunidad para indicar un dato curioso, en esta serie numérica: cuando Hernández publique La vuelta de Martín Fierro en 1879, entonces el poema tendrá 33 cantos.

3 Esta reconstrucción de la exhibición concreta del cuadro de Blanes en su propio taller en Montevideo puede leerse en la biografía que sobre Blanes escribe Eduardo de Salterain y Herrera, basándose en crónicas de la época sobre sus exposiciones. Ver Salterain y Herrera (1950: 165).

4 ¡Y hasta fragancias! La Tribuna, por ejemplo, en un artículo titulado "La exposición de cuadros", anuncia el domingo 28 de julio de 1878 que "los billetes de ingreso a la exposición se venderán envueltos en ramitos de fragante violeta".

5 Lo que se encuentra en esa operación, sin dudas, es la práctica de la transposición según la pensó Steimberg (1993). Si bien Genette (1989) le daba al concepto un sentido más restringido, Steimberg lo amplió de manera productiva: no se trataría solo de la transformación de un texto en otro, sino que permitiría pensar la transformación, reconfiguración y actualización de un objeto artístico en su pasaje a otros medios y a otros lenguajes: de la literatura, entonces, a la pintura, la ilustración, la historieta o el cine, o viceversa (Steimberg 1993: 87-88). Los procedimientos de transformación que implica toda transposición son numerosos; algunos de los más importantes son la reducción, la inflación, el achatamiento o la matización. En ese sentido, para Steimberg la ilustración podría pensarse -como cualquier otra transposición de un texto- como una lectura del texto, como su actualización y resignificación, y esta suele recorrer alguno de los dos caminos que son también habituales en la crítica: en primer lugar, la transposición puede confirmar ciertos estereotipos de lectura, cierta lectura sedimentada, reproducida y naturalizada de la época, atenta sobre todo al tema o al asunto, los núcleos centrales del relato y el desenlace; en segundo lugar, puede desplegar sentidos que estaban ocultos en las lecturas sociales del texto transpuesto, atenta ahora a los niveles diferenciados y complejos del texto, no solo temáticos sino también retóricos (Steimberg 1993: 90-91).

6 Julio Schvartzman, en "El gaucho letrado" (1996), sintetiza el artefacto y la fórmula del género gauchesco en "la frase con la que hacia 1870 Lucio V. Mansilla, que a veces hacía gauchesca en prosa, presenta la historia del paisano Miguelito, en Una excursión a los indios ranqueles: 'Hablaré como él habló'”. Esa fórmula casi perfecta del género que se encuentra como una gema en Mansilla debería ser reformulada - para Schvartzman-del siguiente modo: escribiré como él habló. Schvartzman ha retomado recientemente esas hipótesis sobre las relaciones entre la escritura de Mansilla y el género gauchesco en Letras gauchas (2013).

7 Para la noción de ekphrasis ver Mitchell (1994).

8 Rojas, en el prólogo con que acompaña la publicación del poema que hizo en 1937, propone que en su edición "no se reproduce el cuadro de Blanes como simple ornato del folleto, sino como necesario complemento del poema, por ser éste una animada descripción de las figuras de aquel, a la vez que una interpretación de las mismas." y que "su descripción desentraña el espíritu del grupo heroico y hace hablar a cada personaje, completando así la obra del pintor con la del poeta" (1937: 340 y 342, las cursivas son mías). Halperín Donghi, asimismo, en la breve reflexión que dedica a este poema en José Hernández y sus mundos, ha reparado en ese doble procedimiento del texto: "el núcleo de esta composición relativamente extensa (33 sextinas) lo constituye una sucesión de concisos retratos físicos de la gente 'subalterna' incluida en el lienzo y una reconstrucción de su personalidad a partir de los rasgos de aquéllos” (1985: 301, las cursivas son mías).

9 El verso “¡ah cuadro que da calor” merece un comentario aparte. Resuena, por detrás, algún verso de Bartolomé Hidalgo y tal vez de algún otro gauchesco: “Ah! Pingo, que da calor!”, se lee en el cuarto verso de uno de los diálogos de Hidalgo, el "Diálogo entre Jacinto Chano, capataz de una estancia en las islas del Tordillo, y el gaucho de la Guardia del Monte” (Hidalgo, 1940). Pero en Hernández la admiración del gaucho por el caballo o pingo se ha transformado en admiración y calor por un cuadro, una pintura: jarte!

10 Recordemos los términos en que, en dos oportunidades al menos, Hernández se distanciaba de esa tradición de representación y construcción de la voz y la figura del gaucho: "Quizás la empresa habría sido para mí más fácil y de mejor éxito, si sólo me hubiera propuesto hacer reír a costa de su ignorancia, como se halla autorizado por el uso, en este género de composiciones"; "Por lo demás, espero, mi amigo, que Ud. lo juzgará con benignidad, siquiera sea porque Martín Fierro no va de la ciudad a referir a sus compañeros lo que ha visto y admirado en un 25 de Mayo u otra función semejante, referencias algunas de las cuales, como el Fausto y varias otras, son de mucho mérito ciertamente, sino que cuenta sus trabajos, sus desgracias, los azares de su vida de gaucho, y Ud. no desconoce que el asunto es más difícil de lo que muchos se imaginarán" (Hernández, 2001: 5-6).

11 Tal vez no sea vano explicitar de nuevo que el poema de Hernández parece relacionarse más estrechamente con la "Carta de Anastasio el Pollo sobre el Beneficio de la Sra. La Grúa”, donde el gaucho Anastasio parece ser víctima del ilusionismo 
de la representación y no parece ser consciente de ella, y no tanto -en este aspecto- con el Fausto, donde el gaucho se muestra, en su relato de lo visto en la ópera, no sólo muy consciente de los artificios del teatro, señalando todo el tiempo cuándo se levanta y cuándo se baja el telón, sino también como un sujeto que puede separarse de la representación y de la ceremonia teatral para mostrarse incluso irónico respecto de ella.

12 Hay que señalar, de todos modos, que durante el siglo XIX la crítica de arte tiene una incipiente y relativa autonomía y que su práctica es por lo general realizada por los mismos escritores que se dedican a la crítica operística, teatral y/o literaria y también a otros géneros usuales en la prensa del siglo XIX. El género discursivo de la crítica artística por otro lado no se termina de perfilar en el siglo XIX y aún incluye un conjunto muy heterogéneo de tipos, formas y expresiones textuales. Dario Gamboni ha mostrado cómo esa autonomía relativa se va consolidando recién hacia fines del siglo XIX, en Europa: si durante buena parte del siglo la crítica de arte se ejerce en un vaivén entre tres polos diferenciados pero porosos (el polo "literario", el polo "científico" y el polo "periodístico"), sobre todo en las últimas décadas del siglo -y debido tanto a la expansión creciente de la prensa como a la modernización del campo artístico, a sus nuevos mecanismos de difusión y consagración de las obras, en relación ya estrecha con el mercado- "la crítica de arte experimentó un proceso de profesionalización en el que el polo periodístico cobró preponderancia, el científico se especializó en 'historia del arte', ocupándose, en principio, del arte del pasado, y el literario fue marginado como 'pura literatura'” (Gamboni 2007: 200). En el Río de la Plata, en la década de 1870, en un contexto en que la autonomía del campo artístico no es sino muy incipiente y aun más lo es su relación con el mercado, es muy esperable entonces que la crítica artística siga compartiendo ciertos procedimientos con la crítica teatral y la crítica literaria (más usuales en la prensa de la época) y tienda a no reparar aún, ante todo, en cualidades plásticas. Aún más, digamos, el “polo literario" en términos de Gamboni, y cierto impresionismo como base para los juicios, parecen atravesar la mayoría de las formas de la crítica en ese momento concreto de nuestra historia. Todo ello nos permite pensar el poema de Hernández como una forma particular de la crítica artística tal como se realiza en nuestro siglo XIX. Y, a la vez, en el sentido de El crítico como artista de Oscar Wilde, como una forma en la que se propone que la crítica de una obra de arte puede ser, ella misma, una obra de arte.

13 Si bien las "reglas, máximas y preceptos" que se cristalizan en el manual de Francisco de Mendoza (1870) nos sirven para pensar algunas cuestiones en torno al cuadro de Blanes y su recepción por Martín Fierro, la problemática específica del género de pintura de historia en el caso de Blanes debe estudiarse ante todo en función de su formación en la academia de Ciseri en Florencia: Ciseri, en efecto, se ha especializado en la pintura histórica y Blanes se forma en esa escuela. Aun así, el manual de Francisco de Mendoza es productivo para pensar en términos de los modos de ver que signan la época y caracterizan las prácticas tanto del pintor como del poeta, así como de los espectadores de la pintura y de los lectores del poema.

14 Guerra, alianza, enemigos, aliados son precisamente - para Josefina Ludmer- algunas de las palabras claves del género gauchesco; pero son también términos que sirven para pensar el modo en que Blanes concibe la pintura de historia. Así, si bien los géneros son muy diferentes, implican códigos diversos y ocupan lugares diferentes en el sistema literario y artístico del siglo XIX, se espejan y se proyectan de todos modos uno en el otro, encontrando una serie común de problemas.

15 "Y animando aquella gente / que a lidiar se precipita / mientras se mueve y agita / oyendolo hablar al viejo, / hay uno que dende lejos / le muestra una crucesita" (2014: 102).

16 "El otro de camiseta, / ya deja ver que es soldao; / está muy arremangao / como hombre resuelto á todo, / se le conoce en el modo / que ha sido algún desalmao" (2014: 102).

17 "Soldaos" para Fierro quizá no implica un genérico que agrupe a todas las figuras, sino que designa precisamente a los subordinados: es decir, aquellos que no son ni comandantes, ni mayores, ni tenientes, ni sargentos, ni cabos: soldados, es decir, la escala más baja en la jerarquía militar

18 Así, en la Ida se lee lo siguiente: "Yo llevé un moro de número / sobresaliente el matucho! / Con él gané en Ayacucho / más plata que agua bendita- / Siempre el gaucho necesita / Un pingo pa fiarle un pucho. / Y cargué sin dar más gueltas / con las prendas que tenía, / jergas, ponchos, cuanto había / en casa, tuito lo alcé- / A mi china la dejé / medio desnuda ese día. // No me faltaba una guasca, / esa ocasión eché el resto; / bozal, maniador, cabresto, / lazo, bolas y manea... / iEl que hoy tan pobre me vea / tal vez no crea todo esto!!” (Hernández 2001: 116-117).

19 "La garabina y el sable / que están tirados allí, / pensé yo al verlos así: / o alguno se ha hecho avestruz / o son de aquel de la cruz, / que los ha dejao allí."

20 Si para Francisco de Mendoza (1870) el ordenamiento de los grupos de figuras es clave a la hora de la composición, habría que señalar que ese ordenamiento no es nada azaroso en el cuadro de Blanes. Así, basándonos en los cargos militares que según Ricardo Rojas (1937) tendrían los diversos personajes representados (de los que circulan listas de nombres con variaciones), el ordenamiento de los grupos se muestra como un ordenamiento fuertemente jerárquico: en el centro los jefes; al margen, fundamentalmente, los soldados. La mirada de Fierro va, en ese sentido, del centro a los márgenes: del jefe a la gente subalterna. De las nueve o diez figuras a las que Martín Fierro presta atención, solo dos no serían meros soldados. 
Orbis Tertius, vol. XXIII, nº 27, e069, junio 2018. ISSN 1851-7811

21 Ello podría verse en una serie que va desde la "Relación que hace el gaucho Ramón Contreras a Jacinto Chano de todo lo que vio en las Fiestas Mayas de Buenos Aires, en el año 1822” de Bartolomé Hidalgo al Fausto de Estanislao del Campo; también desde el periódico Aniceto el Gallo, en cuyo n ${ }^{\circ} 3$ Ascasubi discute en lengua gauchesca la interpretación de las figuras alegóricas representadas en las estampas que adornaron la pirámide de Mayo durante las fiestas mayas de 1853, a la "Carta..." que Hernández publica en 1878 comentando el cuadro de Blanes o al "Cantalicio Quirós y Miterio Castro en un baile del Club Uruguay” (1883) de Lussich, en que un gaucho le narra al otro su visión particular de un concierto musical y un baile de la alta sociedad en el Club Uruguay de Montevideo. 